\title{
Dysfunctional Attitude and Self-Blame: Effect on Self-Esteem and Self-Conscious Emotions among Adolescents
}

\author{
Dr. Mandeep Kaur ${ }^{1}$, Inderbir Kaur ${ }^{2}$
}

\section{ABSTRACT}

The present studied investigated the effect of dysfunctional attitude and self-blame on selfesteem and self-conscious emotions (shame and guilt) among adolescents. 122 adolescents between 15-19 years were taken in for the study. They were students of $11^{\text {th }}$ and $12^{\text {th }}$ standard of various public and private schools of Patiala. All the participants were given Child and Adolescent Dysfunctional Attitude Scale (CADAS), Attribution Blame Questionnaire (ABQ), Multidimensional Self-Esteem Inventory (MSEI), Test of Self Conscious Affect- Adolescents (TOSCA-A). Results showed that adolescents high on dysfunctional attitude are low on self esteem and high on shame whereas adolescents high on self-blame were also low on self-esteem and high on shame. The study also shows interaction between dysfunctional attitudes and selfblame.

Keywords: Dysfunctional Attitude, Self-Blame, Self-Conscious Emotions, Self-Esteem

Adolescence is a transitional developmental stage that starts with the onset of puberty and end with the acceptance of adulthood roles. In all societies, adolescence denotes moving from immaturity to adulthood, and preparing for the future (Steinberg, 2008). This period involves several biological, cognitive and psychosocial changes and during adolescence youth are faced with difficulties that are cognitive, relational and biological in nature (Williams et al., 2002; Susman \& Don, 2009). Indicators and predictors of adolescent's mental health are essentially connected with not only the present but future health and health-related behaviours also (Galambos \& Costigan, 2003). Negative patterns of thinking and maladaptive information processing, termed cognitive vulnerabilities, have been shown to contribute to the development of depressive symptoms in adolescents who activate these vulnerabilities in response to negative events (Lewinsohn, Rhode, \& Seley, 1994, 1998 Abela, 2001; Hankin \& Abramson, 2002). Cognitive vulnerability theories (Beck’s Cognitive Theory, Hopelessness Theory, and CognitiveVulnerability Transactional Stress Model) propose that individuals who possess cognitive vulnerability to depressive symptoms are more likely to develop depressive symptoms following the occurrence of negative life event than individuals who do not possess cognitive vulnerabilities. Beck assigns a central role to the "cognitive triad" in depression; namely,

\footnotetext{
${ }^{1}$ Associate Professor, Department of Psychology, Punjabi University, Patiala

${ }^{2}$ PhD Research Scholar, Department of Psychology, Punjabi University, Patiala

(C) 2015 I M Kaur, I Kaur; licensee IJIP. This is an Open Access Research distributed under the terms of the Creative Commons Attribution License (http://creativecommons.org/licenses/by/2.0), which permits unrestricted use, distribution, and reproduction in any Medium, provided the original work is properly cited.
} 


\section{Dysfunctional Attitude and Self-Blame: Effect on Self-Esteem and Self-Conscious \\ Emotions among Adolescents}

pervasive negative attitudes that the depressed individual has towards himself, towards the outside world, and towards his future. Self-blame may also increase depressive episodes in addition to serving as a symptom of an episode. Individuals high on self-blame may have dysfunctional attitude as they loose faith and look at things from a negative perspective. Specifically, individuals high in self-criticism are preoccupied with achievement goals, and are especially susceptible to depression when they feel they are unable to meet high standards set by themselves and/or others.

\section{DYSFUNCTIONAL ATTITUDE}

According to Beck (1967) dysfunctional attitude consists of concept of arbitrary inference, selective abstraction, overgeneralization, magnification or minimization or even inexact labeling. Dysfunctional attitudes is operationally defined from three aspects according to Weissman and Beck (1978), they are vulnerability referring to the pessimistic attitudes that tend to exaggerate negative consequences of an action, whereas success perfectionism means the attitudes with the perfectionist criteria that could not bear with any mistakes done in one's actions, and, social approval is defined as dependency on others' approval for a satisfactory life of one self.

\section{Beck's Cognitive Theory (Beck, 1987)}

(Beck, 1987; Clark \& Beck, 1999) proposes that dysfunctional attitudes are part of the etiology in the development of depressive symptoms. Dysfunctional attitudes are defined as cognitive distortions that interact with stressful events to produce depressive symptoms. This cognitive vulnerability theory hypothesizes that individual who use dysfunctional attitudes (I am worthless unless I am pretty.) are at risk for the development of depressive symptoms. Dysfunctional attitudes can be held regarding achievement (If I fail my math test, I am a failure as a person), interpersonal factors (I am nobody if I do not have friends), and/or intrapersonal factors (I am nobody unless I am skinny). Findings from research with both adults and adolescents revealed that dysfunctional attitude place individuals at increased risk for the development of depressive symptoms and recurrence of depressive disorders (Farmer, Harris, Redman, Mahmood, Sadler, \& McGuffin, 2001; Lewinsohn, Joiner, \& Rhode, 2001; Weich, Churchill, \& Lewis, 2003).

\section{SELF-BLAME}

Self-blame is one of the most toxic forms of emotional abuse. It amplifies our perceived inadequacies, and paralysis us before we can even began to move forward. Self-blame essentially means that one assumes personal responsibility for the occurrence of a traumatic event often when it is clear that the individual is actually the victim (Janoff-Bulman, 1979). Self-blame may also increase depressive episodes in addition to serving as a symptom of an episode (Beck, 1967). According to Frazier and Schauben (1994), one psychological variable that plays a significant role in an individual's recovery from a negative event is the attributions he/she makes for cause of that event. According to researchers, there are several reasons for people to try and ascribe meaning to their misfortune, often through causal attributions (Janoff-Bulman, 1979; 


\section{Dysfunctional Attitude and Self-Blame: Effect on Self-Esteem and Self-Conscious Emotions among Adolescents}

Taylor, 1983; Shaver, 1985). According to Janoff-Bulman (1979) we have certain underlying assumptions about the world we live in, which are basic to our daily activities and understanding of our world. But, negative life events like major illness, criminal victimization or an accident may challenge these basic assumptions (Perloff, 1983). The occurrence of negative event challenges an individual's belief that the world is predictable and controllable and thus leading to a search for meaning (Abramson, Seligman, \& Teasdale, 1978). The attribution search for meaning after a negative life event may influence subsequent well-being. Research has shown that individuals often seem to make attributions about causality that are focused on the self (Bard \& Sangrey; Bulman \& Wortman, 1977; Janoff-Bulman, 1979; Miller \& Porter, 1983; Abbey, 1987). Bulman and Wortman (1977) have argued that self-blame should be viewed as adaptive because it increases perceptions that one can avoid similar events in the future. The perception of future avoid ability confirms a belief in personal control over one's outcomes and thus defends against the conclusion that events are random and uncontrollable.

\section{SELF-ESTEEM}

The adolescent transition is characterized by the emergence of a more self-directed and selfregulated mind (Keating, 2004). Self-regulation is advanced through an executive suite of capabilities. A developing executive control monitors and manages cognitive resources during adolescence (Kuhn \& Pease, 2006) which relates to opportunities for growth and positive development. Self-esteem is the evaluative aspect of the self concept that corresponds to an overall view of self as worthy or unworthy (Baumeister, 1998). This is embodied in Coopersmith's (1967) classic definition of self-esteem:

"The evaluation which an individual makes and maintains with regard to himself, it expresses an attitude of approval and indicates the extent to which an individual believes in himself to be capable, significant, successful and worthy".

While the level of global self-esteem is generally reported to be relatively high during adolescence, it drops dramatically when children enter adolescence (Major, Barr, Zubet, \& Babey, 1999; Robins, Trzesniewski, Tracy, Gosling, \& Potter, 2002). The drop in self-esteem could be attributed to significant changes that take place during the early transition period. During adolescence, reported concern over social evaluation rises sharply as compared to childhood (Westenberg, Drewes, Goedhart, Siebelink, \& Treffers, 2004), reported daily selfconsciousness peaks (Rankin, Lane, Gibbons, \& Gerrard, 2004), and adolescents more frequently interpret themselves as being the target of social evaluation (leading to such phenomena as the imaginary audience; Elkind \& Bowen, 1979).

\section{SELF-CONSCIOUS EMOTIONS}

The increased vulnerability to emotional difficulties during adolescence may be related to the variety of physiological, psychological, relational and environmental changes that characterize 


\section{Dysfunctional Attitude and Self-Blame: Effect on Self-Esteem and Self-Conscious Emotions among Adolescents}

the transitional period that is adolescence. According to Michael Lewis, a way of classifying the different emotions is by operating with a distinction between self-conscious and non-self conscious emotions. Whereas the basic primary emotions do not involve self-consciousness, the more complex emotions do. The self-conscious emotions involve elaborate cognitive processes as they all come through self reflection and involve a concept of self. Self Conscious Emotions arise from attributional processes in which the individual makes an internal attribution (Lewis, 1992, 2002). Studies have shown that internal attribution for failure tends to produce guilt and shame, and internal attribution for success tends to produce guilt. Self-Conscious Emotions play a pivotal role in motivating and regulating people's thoughts, feelings and behaviour (Campos, 1995; Fischer \& Tangney, 1995). Guilt and shame are characterized by feelings of distress arising in response to personal transgressions (Baumeister, Stillwell, \& Heatherton, 1994; Smith et al., 2002; Tangney \& Dearing, 2002; Tangney et al., 2007; Wolf et al., 2010). Shame emerges as a result of internal, stable, and global attributions about one's self (Tracy \& Robins, 2004). When individuals make internal, specific, and unstable attributions it leads to feelings of guilt about one's actions, which result in negative feelings about specific behaviour (Tracy \& Robins, 2004). With shame the individual focuses on one's bad self versus the bad behaviour (Tangney, 1996). Shame leads to an individual thinking how one might look to others (Tangney, Wagner, \& Gramzow, 1992). Whereas in guilt, people do not focus on themselves but rather the event that caused negative evaluation (Tangney, 1996). Shame and guilt are most researched self-conscious emotions and shame has been found to be more maladaptive of the two. Research over the past two decades has shown that shame is related to a wide variety of psychological symptoms including low self-esteem, depression, anxiety, eating disorder, post traumatic stress disorder (PTSD) and suicidal ideation (Tangney, Stuewig, \& Mashek, 2007). Tangney's (1992) study with undergraduates found that participants considered to be shame prone were more likely to be maladjusted.

\section{METHOD}

\section{Sample}

Out of the total 315 adolescents, a total of 122 adolescents ( 71 females and 51 males) were screened for the present study. The adolescents were given Child and Adolescent Dysfunctional Attitude Scale (CADAS) by D'Alessandro \& Abela (2001) and Attribution Blame Questionnaire (ABQ) by Graham and Juvonen (1998). Thus, total of 122 adolescents (high and low on selfblame and dysfunctional attitude) were screened in for further study. Their age ranged between 15-19 years and they were students of $11^{\text {th }}$ and $12^{\text {th }}$ standard of various public and private schools of Patiala. All the participants were given Child and Adolescent Dysfunctional Attitude Scale (CADAS), Attribution Blame Questionnaire (ABQ), Test of Self Conscious AffectAdolescents (TOSCA-A) and Multidimensional Self-Esteem Inventory (MSEI). 


\section{Dysfunctional Attitude and Self-Blame: Effect on Self-Esteem and Self-Conscious Emotions among Adolescents}

\section{Measures}

MULTIDIMENSIONAL SELF-ESTEEM INVENTORY (MSEI) (O’Brien \& Epstein, 1988)

Self-esteem of adolescents is measured using Multidimensional Self-Esteem Inventory (MSEI) by O’Brien and Epstein (1988). The inventory is divided into two sections with 61 and 55 items in each section respectively. The scale is a 5 point likert scale ranging from "1-completely false to 5-completely true”. It measures self-esteem on 11 dimensions but for this study an overall self-esteem score is taken. This measure demonstrated an internal consistency of .80 and the reliability is .85 .

\section{CHILD AND ADOLESCENT DYSFUNCTIONAL ATTITUDE SCALE (CADAS;}

\section{D’Alessandro \& Abela, 2001)}

The child and adolescent dysfunctional attitude scale (CADAS) is developed by D'Alessandro and Abela in 2001. It is an adaptation and extension of the Dysfunctional attitude scale (DAS; Weissman, 1979; Weissman \& Beck, 1978). It includes 22 items which are rated on a 6 point likert scale ranging from 1-stongly disagree to 6-strongly agree. It measures dysfunctional attitudes i.e. depressogenic schemata in children and adolescents. The scale has an alpha coefficient of .87 and three week test-retest reliability of 22 item CADAS is .87.

TEST OF SELF CONSCIOUS AFFECT-ADOLESCENTS (TOSCA-A; Tangney, Wagner \& Gramzow, 1991)

Measure of shame and guilt is Test of Self Conscious Affect-Adolescent (TOSCA-A). The measure consists of 15 scenarios (10 negative $\& 5$ positive) that adolescents are likely to face in everyday life. Item number 2, 4, 6, 11, 13 are positive items. Each scenario is followed by 4 responses that assess guilt proneness, shame proneness, alpha pride and beta pride. In the current study response items assessing alpha pride and beta pride were dropped because our study focused on guilt and shame. The present version consisted of 15 scenarios with two response items (Guilt proneness and Shame proneness). An example is "while playing around, you throw a ball and it hits your friend's face”, followed by items such as 'I would feel stupid that I can't even throw a ball' (Shame proneness) or 'I would apologize and make sure my friend feels better' (Guilt proneness). In adolescent sample the measure has high level of internal consistency (.81 for guilt subscale and .77 for shame subscale) and test retest reliability (Tangney, 1996; Tangney, Wagner, Hill-Barlow, \& Gramzow, 1998).

ATTRIBUTION BLAME QUESTIONNAIRE (ABQ; Graham and Juvonen, 1998)

Attribution Blame Questionnaire (ABQ) measures the levels of self blame characteristics of subject in victimized situations. This questionnaire consists of 4 negative scenarios followed by 12 responses for each. The subject s asked to imagine him/her in a particular situation. Each response item is rated on 5 point likert scale. This measure is divided into two parts i.e. characterological self blame (CSB) and behavioural self blame (BSB), but for this study we 


\section{Dysfunctional Attitude and Self-Blame: Effect on Self-Esteem and Self-Conscious Emotions among Adolescents}

combined the two to get an overall score of self blame. This measure has high levels of internal consistency at both times (.85 \& .86) respectively.

\section{Statistical Analyses}

The data was processed to obtain the following information:

Analysis of Variance (2×2 ANOVA) was applied for analyzing association of Self-Blame and Dysfunctional attitudes with Self-esteem and Self Conscious Emotions in adolescents.

\section{RESULTS AND DISCUSSION}

Table 1: Comparison of Means, SDs and F-ratios for Self-Esteem in relation to Attitude and self-blame

\begin{tabular}{|l|l|l|l|l|}
\hline VARIABLES & LEVELS & MEANS & SD & \multirow{2}{*}{ F-RATIO } \\
\hline \multirow{2}{*}{ Attitude } & Dysfunctional & 366.28 & 20.58 & \multirow{2}{*}{$8.778^{* *}$} \\
\cline { 2 - 4 } & functional & 391.59 & 35.38 & \multirow{2}{*}{$4.525^{* *}$} \\
\hline \multirow{2}{*}{ Self-Blame } & High & 369.85 & 28.38 & \\
\cline { 2 - 5 } & Low & 388.03 & 27.57 & \\
\hline
\end{tabular}

$* * \mathrm{p}<0.01^{*}$

$\mathrm{p}<0.05$

Table 2: ANOVA Summary for the effect of Attitude and self-blame for Self-Esteem

\begin{tabular}{|l|l|l|l|l|}
\hline SOURCE OF VARIANCE & SS & DF & MS & F \\
\hline Attitude (A) & 7931 & 1 & 7931 & $8.778^{* *}$ \\
\hline Self-Blame (B) & 4088 & 1 & 4088 & $4.525^{* *}$ \\
\hline AB & 950 & 1 & 950 & $1.052 \mathrm{~ns}$ \\
\hline Error & 54207 & 60 & 903 & \\
\hline
\end{tabular}

${ }^{* *} \mathrm{p}<0.01$

${ }^{*} \mathrm{p}<0.05$

Ns=Non-Significant

Table 3: Comparison of Means, SDs and F-ratios for Shame in relation to Attitude and selfblame

\begin{tabular}{|l|l|l|l|l|}
\hline VARIABLES & LEVELS & MEANS & SD & \multirow{2}{*}{ F-RATIO } \\
\hline \multirow{2}{*}{ Attitude } & Dysfunctional & 47.23 & 4.12 & \multirow{2}{*}{$0.043 \mathrm{~ns}$} \\
\cline { 2 - 4 } & functional & 46.95 & 5.40 & \\
\hline \multirow{2}{*}{ Self-Blame } & High & 47.85 & 4.43 & \multirow{2}{*}{$1.311 \mathrm{~ns}$} \\
\cline { 2 - 4 } & Low & 46.33 & 5.09 & \\
\hline
\end{tabular}

Ns=Non-Significant 
Table 4: ANOVA Summary for the effect of Attitude and self-blame for Shame

\begin{tabular}{|l|l|l|l|l|}
\hline SOURCE OF VARIANCE & SS & DF & MS & F \\
\hline Attitude (A) & 0.9 & 1 & 0.9 & $0.043 \mathrm{~ns}$ \\
\hline Self-Blame (B) & 28.9 & 1 & 28.9 & $1.311 \mathrm{~ns}$ \\
\hline AB & 364.5 & 1 & 364.5 & $16.559^{* *}$ \\
\hline Error & 1320.9 & 60 & 22.0 & \\
\hline
\end{tabular}

${ }^{* *} \mathrm{p}<0.01$

Ns=Non-Significant

Table 5: Means of shame scores showing interaction of Attitude and self-blame.

\begin{tabular}{|l|l|l|l|}
\hline \multicolumn{2}{|l|}{ Variables } & Attitude \\
\hline \multicolumn{2}{|c|}{} & Dysfunctional & functional \\
\hline \multirow{2}{*}{ Self-Blame } & High & 50.70 & 45.00 \\
\cline { 2 - 4 } & Low & 43.75 & 48.90 \\
\hline
\end{tabular}

Figure 1: Means of shame scores showing interaction of Attitude and self-blame.

\section{Attidude X Self Blame}

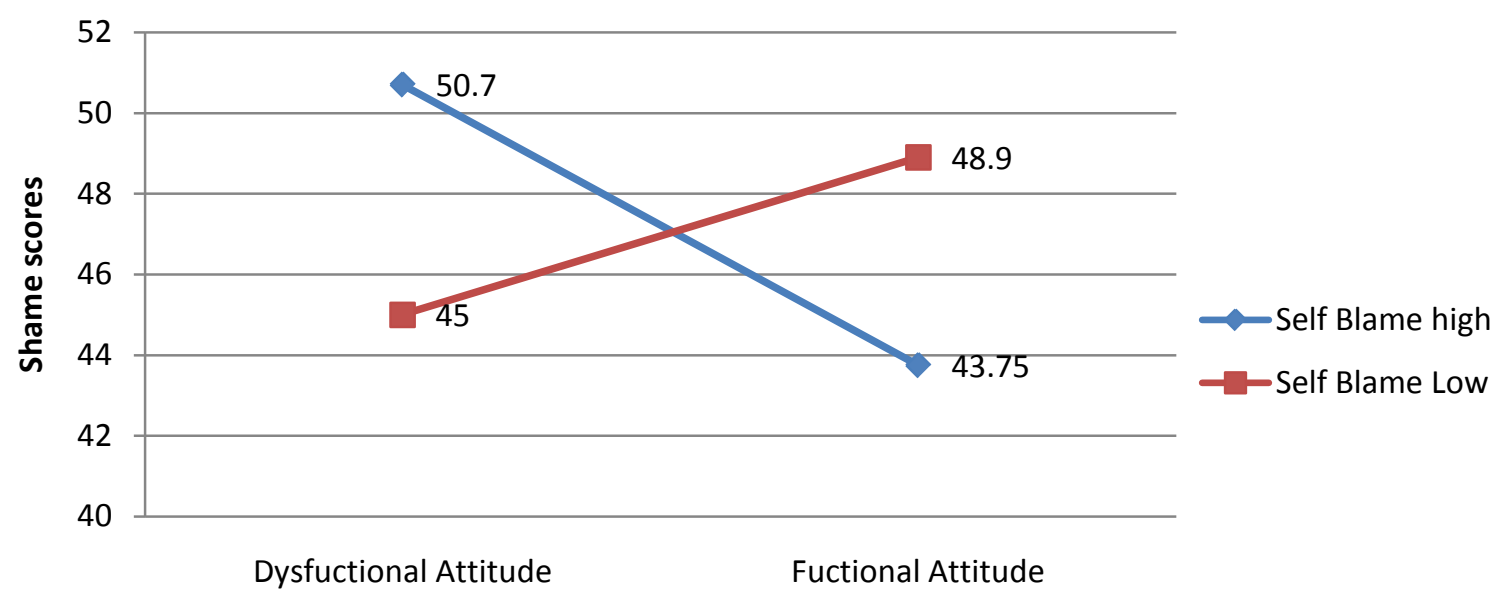

Attitude 


\section{Dysfunctional Attitude and Self-Blame: Effect on Self-Esteem and Self-Conscious Emotions among Adolescents}

Table 6: Comparison of Means, SDs and F-ratios for Guilt in relation to Attitude and self-blame

\begin{tabular}{|l|l|l|l|l|}
\hline VARIABLES & LEVELS & MEANS & SD & \multirow{2}{*}{ F-RATIO } \\
\hline \multirow{2}{*}{ Attitude } & Dysfunctional & 49.78 & 6.25 & \multirow{2}{*}{$1.513 \mathrm{~ns}$} \\
\cline { 2 - 4 } & functional & 47.86 & 5.15 & \\
\hline \multirow{2}{*}{ Self-Blame } & High & 50.65 & 5.86 & \multirow{2}{*}{$5.475^{*}$} \\
\cline { 2 - 4 } & Low & 46.99 & 5.54 & \\
\hline
\end{tabular}

Ns-Non significant

$* \mathrm{p}<0.05$

Table 7: ANOVA Summary for the effect of Attitude and self-blame for Guilt

\begin{tabular}{|l|l|l|l|l|}
\hline SOURCE OF VARIANCE & SS & DF & MS & F \\
\hline Attitude (A) & 45.8 & 1 & 45.8 & $1.513 \mathrm{~ns}$ \\
\hline Self-Blame (B) & 165.9 & 1 & 165.9 & $5.475^{*}$ \\
\hline AB & 16.4 & 1 & 16.4 & $0.540 \mathrm{~ns}$ \\
\hline Error & 1817.6 & 60 & 30.3 & \\
\hline
\end{tabular}

Ns-Non significant

${ }^{*} \mathrm{p}<0.05$

\section{RESULTS}

Results of $2 \times 2$ ANOVA showed that main effect of dysfunctional attitude was found to be significant $[\mathrm{F}(1,60)=8.778,(\mathrm{P}<0.01)]$ as adolescents high $(366.28)$ on dysfunctional attitude were low on self-esteem in comparison to adolescents low (391.59) on dysfunctional attitude. The main effect of self-blame was also found to be significant [F $(1,60)=4.525,(\mathrm{P}<0.01)]$ as adolescents high (369.85) were low on self-esteem as compared to adolescents low(388.03) on self-blame. In table no.2, adolescents high and low on dysfunctional attitude did not show significant differences on shame scores but the little variation in mean differences show that adolescents high on dysfunctional attitude $(M=47.23)$ were high on shame than adolescents low on dysfunctional attitude ( $M=46.95)$. Similarly, the main effect of Self-Blame was also found to be non-significant $[\mathrm{F}(1,60)=0.043 \mathrm{~ns}]$, but the little variation in the mean differences shows that adolescents high on self-blame $(\mathrm{M}=47.85)$ were high on shame than adolescents low on self-

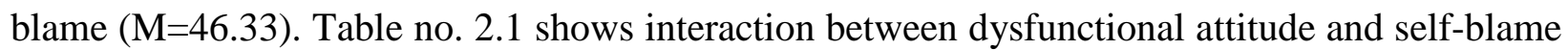
$[(1,60)=16.559,(\mathrm{P}<0.01)]$. Table no.3 shows that adolescents high and low on dysfunctional attitude did not show significant differences on guilt scores but the little variation in mean differences show that adolescents high on dysfunctional attitude ( $M=49.78)$ were high on guilt than adolescents low on dysfunctional attitude( $\mathrm{M}=47.86)$. The main effect of Self-blame was found to be significant $[\mathrm{F}(1,60)=5.475$, $(\mathrm{P}<0.05)]$ as adolescents high $(50.65)$ on self-blame were high on guilt as compared to adolescents low (46.99) on self-blame but it was contrary to the hypothesis. 


\section{Dysfunctional Attitude and Self-Blame: Effect on Self-Esteem and Self-Conscious Emotions among Adolescents}

\section{DISCUSSION}

The present study attempts to investigate the effect of dysfunctional attitude and self-blame on self-esteem self-conscious emotions (shame and guilt). The findings revealed that adolescents low on dysfunctional attitude were high on self-esteem. Empirical research has shown that people seek to maintain, enhance and protect their self-esteem in many ways (Baumeister, 1998). Several studies have linked high self-esteem to many positive outcomes like healthy social relationships (Murray et al., 2000; Neyer \& Asendorpf, 2001; Trzesniewski et al., 2003), positive perception by peers (Robins et al., 2001) and healthy subjective well-being (Trzesniewski et al., 2003). Number of studies have demonstrated that high self-esteem is strongly related to the beliefs people hold about themselves as high self-esteem people believe that they are intelligent and attractive (Baumeister at al., 2003). On the other hand low self-esteem has been linked to number of problematic outcomes including anti-social behaviours such as depressive symptoms, bullying and health problems (Ma, 2002; Veselsk et al., 2009).

Most researchers support the idea that self-esteem decreases in early adolescence, with considerable decline in achievement, sense of worth and academic motivation (Baldwin \& Hoffman2002; Baldwin, 2008). As many as one in five youths report high self esteem in late childhood, and show decrease in feelings of self-worth during early adolescence (DuBors \& Tenadale, 1999). Negative self-esteem in young adolescents is predictive of significant difficulties in emotional, behavioural and academic functioning (Silverthorn \& Crombie, 2002). High self-esteem is one such factor that is likely to moderate the association between dysfunctional attitudes, negative life events, and depressive symptoms. Researchers have argued that youth possessing cognitive vulnerability to depression are able to maintain positive selfevaluations following negative life events if they posses high levels of self-esteem (Southall \& Roberts, 2002). Previous research using adult samples has shown that high self-esteem buffers against the onset of depressive symptoms following negative events in individuals possessing cognitive vulnerability to depression (e.g., Abela, 2002; Metalsky et al., 1993).

The findings also show that adolescents high on self-blame were low on self esteem. Researchers (Katz \& Burt, 1988) have suggested that self blame is maladaptive because it undermines selfesteem and infuses feelings of helplessness. Formica (2013) also states that self blame amplifies our perceived inadequacies and paralysis us before we can begin to move forward. The selfcritical personality type is described as one that carries an incessant need for self-sufficiency and is plagued with feelings of failure, worthlessness, self-doubt and inferiority (Blatt \& Homann,1992; Blatt \& Zuroff, 1992).

The view that self-blame is maladaptive has received some empirical support (Kiecolt, Glaser \& Williams, 1987; Katz \& Burt, 1988; Delahanty, Herberman, Fullerton, Uranso, Craig, Hayward, \& Baum, 1997). In one study Katz and Burt (1988) studied post rape adjustment by asking female victims to rate their immediate post rape reactions and current reactions. The findings 


\section{Dysfunctional Attitude and Self-Blame: Effect on Self-Esteem and Self-Conscious Emotions among Adolescents}

suggest that greater self-blame was associated with low self-esteem and longer recovery time. People with low self-esteem have negative expectations about their performance and as a result they may feel anxious. They tend to blame themselves when thay do poorly and feel depressed. Another study showed that adolescents, to some degree, blamed their own (controllable) behaviour when explaining peer harassment. Victims were found to be low on self-esteem and lonelier in comparison to non-victimized classmates (Graham \& Juvonen, 2002).

Further, the research findings showed no significant differences for shame in adolescents high and low on dysfunctional attitude but the mean trends show that adolescents with dysfunctional attitude were high on shame in comparison to adolescents low on dysfunctional attitude. At its most basic level the individual's appraisal of an event determines the kind of emotion(s) one experiences. Norms become more important in adolescents life (Linn \& Songer, 1991). With shame, an individual put emphasis on one's "bad self" versus the "bad behaviour"( Tangney, 1996). It is the "the sense of exposure" when individual thinks about how one might look to others (Tangney, Wagener, Gramzow, 1992). Previous researches indicate that proneness to shame is related to wide variety of psychological symptoms including dysfunctional attitude, low self-esteem, anxiety, eating disorder symptoms and suicidal ideation (Tangney, Stuewig, \& Mashek, 2007). Beck’s Cognitive Theory (Beck, 1987; Clark \& Beck, 1999) conceptualizes dysfunctional attitude as a cognitive vulnerability that includes negative self schemas containing cognitive distortions. Shame involves a negative evaluation of central aspect of self (Tangney, 1999) and earlier studies have shown that shame proneness is associated with depressogenic attribution style (Harder \& Lewis, 1987; Hoblitzelle, 1987). Tangney's (1992) study revealed that shame prone adolescents were more likely to be psychologically maladjusted. In addition Self Discrepancy Theory (Higgins, 1987) also states that shame is dejection related emotion because it arises from a perceived discrepancy between actual self and ideal self.

The main effect of Self-Blame was also found to be non-significant, but the little variation in the mean differences shows that adolescents high on self-blame $(\mathrm{M}=47.85)$ were high on shame than adolescents low on self-blame ( $M=46.33)$. Greenberg, Watson, and Goldman (1998) emphasized the role of the incapacity of the self to counter self-critical attacks as major factor in the depressogenic process, along with the importance in attending to the harsh negative affect, such as shame and helplessness that results from self-criticism (Greenberg \& Paivio, 1997). The findings get support from Beck's Content Specificity Theory states that each emotional state and psychological disorder has a specific cognitive profile (Beck, 1976; Clark et al., 1999). Subjects who attributed responsibility for negative events to themselves and positive events to the responsibility of others, had a high level of depressive complaints (Berg-Cross, 1997). In a recent study to evaluate their new scale called the sensitivity to put-down scale, Gilbert and Miles (2000) found that self-blame for criticism was associated with social anxiety, depression and shame. Table no. 2.1 shows interaction between dysfunctional attitude and self-blame. Seligman's (1975) theory of learned helplessness suggests that depression results from a belief in 


\section{Dysfunctional Attitude and Self-Blame: Effect on Self-Esteem and Self-Conscious Emotions among Adolescents}

the uncontrollability of outcomes. According to Beck's (1967) theory of depression, the depressed individual blames him/herself for negative outcomes, particularly personal failures. Self-blame for negative events has been shown to be predictive of depression, both concurrently and longitudinally, in the face of negative events that are perceived as important (Mittelstaedt \& Wollert, 1991; Wollert \& Rowley, 1987). Compared to attributions, self-blame seems to have higher concurrent and longitudinal associations with mood (Wollert \& Rowley, 1987). Furthermore, high self-blame is also associated with increased severity and length of depressive episodes (Beck, 1963). It may also lead to enhancing the depressive episodes in addition to serving as a symptom of an episode (Beck, 1963). Harper et al (2002) noted that when a person becomes depressed, his cognitions change. One becomes pessimistic, more critical of oneself and is more likely to blame himself for all the bad situations. Seligman et al (1988) found that selfblaming attributions for failure were related with severity of depression in both unipolar and bipolar depression. Researches in mainland China and with western adolescent samples (Adams et al; Shaher et al., 2004; Abela et al., 2006) have also found that self-blaming strongly predicted depressive symptoms. Adams and colleagues (2009) found strong support for the theory by demonstrating that both dependency and self-criticism represented vulnerabilities to prospective depressive symptoms in at-risk youth. The majority of studies, however, only found support for

selfcriticism as a vulnerability factor (Shahar et al., 2004) suggesting that this personality predisposition may be especially problematic during adolescence.

Adolescents high and low on dysfunctional attitude did not show significant differences on guilt scores but the little variation in mean differences show that adolescents high on dysfunctional attitude ( $M=49.78)$ were high on guilt than adolescents low on dysfunctional attitude( $M=47.86)$. Guilt, involving a negative evaluation of specific behaviour implies internal, specific and rather unstable attributions. According to Attributional Theory of Depression (Gotlib \& Abramson, 1999), guilt is less maladaptive and contributes less to depressive symptoms as compared to shame. The studies of Fontaine et al., (2001), Harder et al., (1992), Stuewig \& McCloskey (2005), and Tangney, Wagner and Gramzow (1992) used Test of Self Conscious Emotions (TOSCA; Tangney et al., 1990) and the results suggested that only shame but not guilt has effect on depression. Guilt may not be bad as guilt prone individuals appear better able to empathize with others and to accept responsibility for negative events, less prone to anger than shame prone people but when angry express directly. Research has also shown that the success of cognitive therapy for treating depression may be linked to the positive effects of regulating shame into more adaptive emotions such as guilt. On the contrary to these studies, empirical studies provide evidence for association of guilt to depression (Alexander, Brewin, Vearnals, Wolff, \& Leff, 1999; Ghatavi, Nicolson, MacDonald, Osher \& Levitt, 2002). Changes in the strength of emotions emerge, as guilt typically increases during adolescence, and shame decreases from adolescence into middle adulthood (Orth, Robins, \& Soto, 2010; Walter \& Burnaford,2006). Overall, during early adolescence, changes emerge in the quality of the emotions as the 


\section{Dysfunctional Attitude and Self-Blame: Effect on Self-Esteem and Self-Conscious \\ Emotions among Adolescents}

perceived controllability of the situations, as well as emotion expectancies, increasingly affect moral decision making (Graham, Doubleday, \& Guarino, 1984).

The main effect of Self-blame was found to be significant $[\mathrm{F}(1,60)=5.475,(\mathrm{P}, 0.05)]$ as adolescents high(50.65) on self-blame were high on guilt as compared to adolescents low (46.99) on self-blame but it was contrary to the hypothesis. Victims who blame themselves feel more guilt, shame and are more likely to experience post-traumatic stress disorder (Arata \& Burkhart, 1996). Guilt reflects feelings about actions that are inconsistent with internalized standards and thus individual blames oneself for inappropriate behaviour.

The present study helps us to understand various issues of adolescence and how our attitudes can influence our perceptions and affect an adolescent emotionally. One tries to form a stronger self and have a positive attitude towards life. Emotional fluctuations are at peak among adolescents as they fight to make an identity in the society. This study has also shown how culture can influence one's emotions and cognitions.

\section{REFERENCES}

Abbey, A. (1987). Perceptions of personal avoidability versus responsibility: How do they differ? Basic and Applied Social Psychology, 8, 3-19.

Abela, J. R. Z. (2001). The hopelessness theory of depression: A test of the diathesis-stress and causal mediation components in third and seventh grade children. Journal of Abnormal Child Psychology, 29, 241-254.

Abela, J. R. Z., Aydin, C., \& Auerbach, R. P. (2006). Operationalizing the "vulnerability” and "stress" components of the hopelessness theory of depression: A multi way longitudinal study. Behaviour Research and Therapy, 44, 1565-1583.

Abela,J. R.Z.(2002).Depressive mood reactions to failure in the achievement domain: A test of the integration of the hopelessness and self-esteem theories of depression. Cognitive Therapy and Research, 26, 531-552.

Abramson, L. Y., Seligman, M. E. P., \& Teasdale, J. D. (1978). Learned helplessness in humans: Critique and reformulation. Journal of Abnormal Psychology, 87, 49-74.

Alexander, B., Brewin, C. R., Vearnals, S., Wolff, G., \& Leff, J. (1999). An investigation of shame and guilt in a depressed sample. British Journal of Medical Psychology, 72, 323338.

Arata, C. M. \& Burkhart, B. R. (1996). Post-traumatic stress disorder among college student victims of acquaintance assault. Journal of Psychology \& Human Sexuality, 8, 79-92.

Baldwin, S. A., \& Hoffmann, J. P. (2002). The dynamics of self-esteem: A growth-curve analysis. Journal of Youth and Adolescence, 31, 101-113.

Bard, M., \& Sangrey, D. (1979). The crime victim's book. New York: Basic Books.

Baumeister, R. F. (1998). The self. In D. T. Gilbert \& S. T. Fiske \& G. Lindzey (Eds.), Handbook of social psychology (4 ed., Vol. 2, pp. 680-740). New York: McGraw-Hill. 


\section{Dysfunctional Attitude and Self-Blame: Effect on Self-Esteem and Self-Conscious \\ Emotions among Adolescents}

Baumeister, R. F., Campbell, J. D., Krueger, J. I., \& Vohs, K. D. (2003). Does high self-esteem cause better performance, interpersonal success, happiness, or healthier lifestyles? Psychological Science in the Public Interest, 4, 1-44.

Beck, A. T. (1967). Depression: Clinical, experimental, and theoretical aspects. New York: Harper \& Row.

Beck, A. T. (1987). Cognitive models of depression. Journal of Cognitive Psychotherapy: An International Quarterly, 1, 5-37.

Blatt, S. J., \& Homann, E. (1992). Parent-child interaction in the etiology of dependent and self critical depression. Clinical Psychology Review, 12, 383-389.

Blatt, S. J., \& Zuroff, D. C. (1992). Interpersonal relatedness and self-definition: Two prototypes for depression. Clinical Psychology Review, 12, 527-562.

Bulman, R. J., \& Wortman, €. B. Attributions of blame and coping in the "real world": Severe accident victims react to their lot. Journal of Personality and Social Psychology, 1977, 35, 351-363

Campos, J. J. (1995). In J. P. Tangney \& K. W. Fischer (Eds.), Self-conscious emotions: The psychology of shame, guilt, embarrassment, and pride (pp. ix-xi). New York: Guilford Press.

Clark R, Anderson NB, Clark VR, Williams DR. 1999. Racism as a stressor for African Americans: a bio psychosocial model. American Psychology. 54: 805-16

Clark, D. A., \& Beck, A. T. (1999). Scientific foundations of cognitive theory and therapy of depression. New York: Wiley.

Clark, D. A., \& Beck, A. T. (1999). Scientific foundations of cognitive theory and therapy of depression. New York: Wiley.

Coopersmith, S. (1967). Parental characteristics related to self-esteem. In, The antecedents of self-esteem (chap. 6, pp. 96-117). San Francisco: Freeman.

DC: American Psychological Association.

Delahanty, D. L., Herberman, H. B., Craig, K. J., Hayward, M. C., Fullerton, C. S., Ursano, R. J., \& Baum, A. (1997). Acute and chronic distress and posttraumatic stress disorder as a function of responsibility for serious motor vehicle accidents. Journal of Consulting and Clinical Psychology, 65, 560-567.

Elkind, D., \& Bowen, R. (1979). Imaginary audience behavior in children and adolescents. Developmental Psychology, 15, 38-44.

Farmer, A., Harris, T., Redman, K., Mahomood, A., Sadler, S., \& McGuffin, P. (2001). The Cardiff depression study: A sib-pair study of dysfunctional attitudes in depressed probands and healthy control subjects. Psychological Medicine, 31, 627-633.

Fischer, K. W., \& Tangney, J. P. (1995). Self-conscious emotions and the affect revolution: Framework and overview. In J. P. Tangney \& K. W. Fischer (Eds.), Self-conscious emotions: The psychology of shame, guilt, embarrassment, and pride (pp. 3-24).New York: Guilford Press. 


\section{Dysfunctional Attitude and Self-Blame: Effect on Self-Esteem and Self-Conscious Emotions among Adolescents}

Galambos, N.L. \& Costigan, C.L. (2003). Emotional and Personality Development in Adolescence. In: Lerner RM, Easterbrooks MA, Mistry J, editors. Handbook of psychology, Vol. 6, Developmental psychology. NJ: John Wiley \& Sons.

Graham, S., \& Juvonen, J. (2002). Ethnicity, peer harassment, and adjustment in middle school: An exploratory study. Journal of Early Adolescence, 22, 173-199.

Graham, S., Doubleday, C., \& Guarino, P. A. (1984). The development of relations between perceived controllability and the emotions of pity, anger, and guilt. Child Development, 55, 561-565

Greenberg, L. S., \& Paivio, S. C. (1997). Working with emotions in psychotherapy. New York: Guilford Press

Greenberg, L., Watson, J. \& Goldman, R. (1998) Process Experiential Therapy of Depression. Handbook of Experiential Psychotherapy: Foundations and Differential Treatment. Guilford, New York, 227-248

Hankin, B. L., \& Abramson, L. Y. (2002). Measuring cognitive vulnerability to depression in adolescence: Reliability, validity, and gender differences. Journal of Clinical Child and Adolescent Psychology, 31, 491-504.

Harder, D.W., Cutler, L., \& Rockart, L. 1992. Assessment of Shame and Guilt and Their Relationships to Psychopathology. Journal of Personality Assessment, 59, 584-604.

Hoblitzelle, Wendy (1987), "Attempts to measure and differentiate shame and guilt: The relation between shame and depression," in the role of shame in symptom formation, ed. $\mathrm{H}$. B. Lewis, Hillsdale, NJ: Erlbaum, (pp. 207-235).

Janoff-Bulman, R. (1979). Characterological and behavioral self blame: Inquiries into depression and rape. Journal of Personality and Social Psychology, 37, 1798-1809.

Katz, B., \& Burt, M. (1988). Self-blame: Help or hindrance in recovery from rape? In A. Burgess (Ed.), Rape and sexual assault handbook, Vol. 2 (pp. 151-168). New York: Garland.

Keating, D. P. (2004). Cognitive and brain development. In R. M. Lerner \& L. D. Steinberg (Eds.), Handbook of adolescent psychology (2nd ed., pp. 45-84). New York: Wiley.

Kiecolt, J. \& Glaser K., \& Williams, D. A. (1987). Self-blame, compliance, and distress among burn victims. Journal of Personality and Social Psychology, 53, 187-193.

Kuhn, D., \& Pease, M. (2006). Do children and adults learn differently? Journal of Cognition and Development, 7, 279-293.

Lewinsohn, P., Joiner, T., \& Rohde, P. (2001) Evaluation of cognitive diathesis-stress models in predicting major depressive disorder in adolescents. Journal of Abnormal Psychology, 110, 203-215.io, Canada.

Lewinsohn, P., Rohde, P., \& Seely, J. (1994). Psychosocial risk factors for future adolescent suicide attempts. Journal of Consulting and Clinic Psychology, 62, 297-305.

Ma, X. (2002). Bullying in Middle School: Individual and School Characteristics of Victims and Offenders School Effectiveness and School Improvement, Vol. 13, No. 1, 63-89. 


\section{Dysfunctional Attitude and Self-Blame: Effect on Self-Esteem and Self-Conscious Emotions among Adolescents}

Major, B., Barr, L., Zubek, J., \& Babey, S.H. (1999). Gender and self-esteem: A meta analysis. In W. Swann \& J. Langlois (Eds.), Sexism and stereotypes in modern society: The gender science of Janet Taylor Spence (pp. 223-253). Washington,

Metalsky, G. I., Joiner, T. E., Hardin, T. S., \& Abramson, L. Y. (1993). Depressive reactions to failure in a naturalistic setting: A test of the hopelessness and self-esteem theories of depression. Journal of Abnormal Psychology, 102, 101-109.

Miller, D. T., \& Porter, C. A. (1983). Self-blame in victims of violence. Journal of Social Issues, 39 (2), 139-152

Mittelstaedt, W. H., \& Wollert, R. (1991). Blame and the development of depressed mood. Canadian Journal of Behavioural Science, 23, 1-11

Murray, S. L., Holmes, J. G., \& Griffin, D. W. (2000). Self-esteem and the quest for felt security: How perceived regard regulates attachment process. Journal of Personality and Social Psychology, 78, 478-498.

Neyer, F. J., \& Asendorpf, J. B. (2001). Personality-relationship transaction in young adulthood. Journal of Personality and Social Psychology, 81, 1190-1204.

Perloff, L. S. (1983). Perceptions of vulnerability to victimization. Journal of Social Issues, 39, 41-61

Rankin, J. L., Lane, D. J., Gibbons, F. X., \& Gerrard, M. (2004). Adolescent self-consciousness: Longitudinal age changes and gender differences in two cohorts. Journal of Research on Adolescence, 14, 1-21.

Robins, R. W., Trzesniewski, K. H., Tracy, J. L., Gosling, S. D., \& Potter,J. (2002). Global selfesteem across the life span. Psychology and Aging,17, 423- 434

Robins, R.W., Hendin, H.M., \& Trzesniewski, K.H. (2001). Measuring global self-esteem: Construct validation of a single item measure and the Rosenberg Self-esteem Scale. Personality and Social Psychology Bulletin, 27, 151-161.

Seligman, M. E. P. (1975). Helplessness: On depression, development, and death. San Francisco: Freeman

Shahar, G., Blatt, S. J., Zuroff, D. C., \& Pilkonis, P. A. (2003). Role of perfectionism and personality disorder features in response to brieftreatment for depression. Journal of Consulting and Clinical Psychology, 71, 629-633

Silverthorn, N., \& Crombie, G. (2002, April). Longitudinal examination of self-esteem from grades 8 to 11: Identification and psychosocial differences of four trajectory groups. In D. L. DuBois (Chair), Change and stability in self-esteem during adolescence: The long and the short of it. Symposium conducted at the Biennial Meeting of the Society for Research on Adolescence, New Orleans, LA.

Southall, D., \& Roberts, J. E. (2002). Attributional style and self-esteem in vulnerability to adolescent depressive symptoms following life stress: A 14-week prospective study. Cognitive Therapy and Research, 26, 563-579

Steinberg, L. (2008). Adolescence. Boston, MA: McGraw-Hill. 


\section{Dysfunctional Attitude and Self-Blame: Effect on Self-Esteem and Self-Conscious Emotions among Adolescents}

Stuewig J \& McCloskey L (2005). The impact of maltreatment on adolescent shame and guilt: Psychological routes to depression and delinquency. Child Maltreatment, 10, 324-336

Susman, E.J., \& Dorn, L.D. (2009). Puberty: Its role in development. In: R.M. Lerner \& L. Steinberg (Eds). Handbook of adolescent psychology ( ${ }^{\text {rd }}$ Ed) (116-151). New Jersey: John Wiley \& Sons, Inc.

Tangney, J. P. (1992). Situational determinants of shame and guilt in young adulthood. Personality and Social Psychology Bulletin, 18, 199-206.

Tangney, J. P. (1999). The self-conscious emotions: Shame, guilt, embarrassment and pride. In T. Dalgleish \& M. Power (Eds.), Handbook of cognition and emotion (pp. 541-568). New York: Wiley.

Tangney, J. P., \& Dearing, R. L. (2002). Shame and guilt. New York: Guilford Press.

Tangney, J., Wagner, P., \& Gramzow, R. (1992). Proneness to shame, proneness to guilt, and psychopathology. Journal of Abnormal Psychology, 101, 469-478.

Tangney, J.P. (1996). Conceptual and methodological issues in the assessment of shame and guilt. Behaviour Research and Therapy, 34, 741-754.

Tangney, J.P., Stuewig, J., \& Mashek, D.(2007).Moral emotions and moral behavior. Annual Review of Psychology, 58, 345-372.

Taylor, S. E. (1983). Adjustment to threatening events: A theory of cognitive adaptation. American Psychologist, 38, 1161-1173.

Tracy, J. L., \& Robins, R. W. (2004a). Putting the self into self-conscious emotions: A theoretical model. Psychological Inquiry, 15(2), 103-125.

Trzesniewski, K. H., Donnellan, M. B., \& Robins, R. W. (2003). Stability of self-esteem across the life span. Journal of Personality and Social Psychology, 84, 205-220.

Veselska, Z., Madarasova Geckova, A., Orosova, O., Gajdosova. B., Van Dijk, J.P., \& Reijneveld, S.A. (2009). Self-esteem and resilience: The connection with risky behavior among adolescents. Addictive Behaviors, 34, 287-291.

Weich, S., Churchill, R. \& Lewis, G. (2003). Dysfunctional attitudes and the commong mental disorders in primary care. Journal of affective disorders, 75, 269-278.

Weissman, A., \& Beck, A. T. (1978, November). Development and validation of the Dysfunctional Attitudes Scale: A preliminary analysis. Paper presented at the annual meeting of the American Educational Research Association, Toronto, Ontario.

Westenberg, P. M., Drewes, M. J., Goedhart, A. W., Siebelink, B. M., \& Treffers, P. D. A. (2004). A developmental analysis of self-reported fears in late childhood through mid adolescence: Social-evaluative fears on the rise? Journal of Child Psychology and Psychiatry, 45, 481-495

Williams, P.G., Holmbeck, G.N. \& Greenley, R. N. (2002). Adolescent Health Psychology. Journal of Consulting and Clinical Psychology, 70, 3, 828 - 842. 